\title{
Cattle trampling of simulated ground nests in rotationally grazed pastures
}

\author{
LAURA PANE, D.J. UNDERSANDER, DAVID W. SAMPLE, GERALD A. BARTELT, AND \\ TRACY A. SCHATTEMAN
}

\begin{abstract}
Authors are research specialist and associate professor, Department of Agronomy, University of Wisconsin (UW), 1575 Linden Drive, Madison, Wisc. 53706; and grassland ecologist, section chief, and seasonal technician, Bureau of Research, Wisconsin Department of Natural Resources (WDNR), 1350 Femrite Drive, Monona, Wisc. 53716.
\end{abstract}

\begin{abstract}
For many grassland songbird species, pastures represent some of the best available breeding habitat in the Upper Midwest. Increasing interest in intensive rotational grazing (IRG) among midwestern livestock farmers may result in an expansion of pasture hectares in the region. We evaluated the effects of several cattle stocking densities on ground nest survival in rotationally grazed cool-season pastures in southwestern Wisconsin. Ground nests were simulated with clutches of 3 unwashed pheasant eggs. We tested 3 rotational grazing systems: a 1-day dairy rotation stocked at 60 head $\mathrm{ha}^{-1}$; a 4-day beef rotation at $15 \mathrm{head} \mathrm{ha}^{-1}$; and a traditional, non-intensive 7-day rotation at 8 head ha ${ }^{-1}$. Paddock size (1.2 ha) and nest density (15 nests paddock $\left.{ }^{-1}\right)$ were held constant. The simulated nests were observed 4 times day $^{-1}$ to document trampling patterns during the herds' diurnal grazing and rumination cycles. Trampling damaged a mean of $75 \%( \pm 3.1 \%)$ of the nests for all 3 treatments during 8 consecutive replications. While the 7-day treatment exhibited a pattern of greater nest trampling during cattle grazing periods than during rumination periods, this pattern was less evident in the 4-day treatment and absent in the 1-day treatment. Increasing vegetation height-density and percent vegetation cover were associated with reduced nest trampling rates, but pasture forage production and removal were not associated with nest damage.
\end{abstract}

Key Words: artificial nest, dummy nest, grassland songbirds, intensive rotational grazing, nest disturbance, nest survival, pastures.

Midwestern populations of some grassland bird species (Table 1) have been declining for several decades (USFWS, unpublished data). While causes of these declines remain poorly understood, habitat loss and disturbance in this largely agricultural region

\footnotetext{
The authors wish to thank Tim Wood, Dan Peschel and their staff, at the Lancaster Agricultural Experiment Station for management of the cattle herd and generous support for this study; Jim Keir, WDNR Prairie Chicken Management Program, for the Ioan of fence chargers; Don Bates, WDNR, for providing culled pheasant eggs; Paul Rasmussen, WDNR Bureau of Research, for statistical assistance; and Todd Peterson and Alan Crossley, WDNR Wildlife Management, as well as other members of the Agriculture Ecosystems Research Project for their help in conceiving and developing this research.

Partial funding for this project was provided by the Federal Aid in Wildlife Restoration Act under Pittman-Robertson Project W-160-P, WDNR, and the UWMadison Department of Agronomy.

Manuscript accepted 9 Oct. 1995.
}

have been implicated (Basore et al. 1986, Castrale 1987, Frawley and Best 1991, Herkert 1994). The adoption of Intensive Rotational Grazing (IRG) by livestock farmers may improve habitat quality for grassland birds in the Midwest.

\section{Dairy Pasturing Systems.}

Dairy farming is common in parts of the Upper Midwest (northeastern Iowa, northern Illinois, Michigan, Minnesota, and Wisconsin) and in the Northeast (Pennsylvania, New York, and New England). In the confinement system currently used by most dairy farmers in these areas, stored grain and hay comprise nearly all of the milking animal's daily intake (Fales 1993). In contrast, in an IRG system pasture vegetation provides the bulk of the bovine diet (Voisin 1959). Row crop and alfalfa fields are converted to non-native cool-season grass pastures and stock are rotated through a series of paddocks of 1-2 ha, at stocking densities of 40-100 head ha ${ }^{-1}$. Livestock are confined to each paddock for a period of $<12$ hours to 2 days and are rotated through the paddocks on a 15-to 40-day, weather-dependent cycle (Undersander et al. 1991). Recent survey data suggest that $>10 \%$ of dairy farmers in Wisconsin are using rotational grazing and the percentage is increasing annually (Undersander, D.J., unpubl. survey data). Conversion to this practice among dairy farmers may result in an increase in the amount of grassy cover available for ground nesting birds.

\section{Grassland Birds and Pasture Habitats.}

Grazing can affect nesting birds indirectly by altering vegetation structure and habitat quality, and directly through trampling or other disturbance of nests. Our goal was to evaluate the effects of cattle stocking density on direct disturbance of ground nests by cattle. Several studies have investigated cattle trampling of ground nests, but none have done so under conditions existing in the midwestern United States.

Bryant et al. (1982) theorized that cattle trampling of ground nests involves a simple linear relationship with the cumulative number of steps taken by each animal and that pasture size influenced the distance traveled. They devised a formula to estimate trampling damage for several non-intensive grazing systems $(\geq 16$ ha pastures; $\leq 3-4$ animals $\mathrm{ha}^{-1}$ ). Whether this relationship holds true for all situations, especially for very high stocking densities, has not been determined.

Results of a study of waterfowl nest survival in Dutch pastures concur with Bryant et al. (1982). Bientema and Müskens (1987) 
Table 1. Grassland bird species for whom breeding populations are declining in U.S.F.W.S. Region 3 (Iowa, Ilinois, Indiana, Michigan, Minnesota, Ohio and Wisconsin).

\begin{tabular}{llll}
\hline Common Name & Latin Binomial & Common Name & Latin Binomial \\
\hline Blue-Winged Teal & Anas discors (L.) & Lark Sparrow & Chondestes grammacus (Say) \\
Bobolink* & Dolichonyx oryzivorus (L.) & Loggerhead Shrike* & Lanius ludovicianus (L.) \\
Clay-Colored Sparrow & Spizella pallida (Swain.) & Ring-Necked Pheasant* & Phasiamus colchicus (L.) \\
Dickcissel* & Spiza americana (Gmelin) & Savannah Sparrow & Passerculus sandwichensis (Gmel.) \\
Eastern Meadowlark* & Sturnella magna (L.) & Short-Eared Owl* & Asio flammeus (Pont.) \\
Field Sparrow* & Spizella pusilla (Wils.) & Upland Sandpiper & Bartramia longicauda (Bech.) \\
Grasshopper Sparrow* & Ammodramus savannarum (Gmel.) & Vesper Sparrow & Pooecetes gramineus (Gmel.) \\
Henslow's Sparrow & Passerherbulus henslowii (Aud.) & Western Meadowlark* & Stumella neglecta (Aud.) \\
Homed Lark & Eremophila alpestris (L.) & & \\
\hline
\end{tabular}

Based on unpublished U.S.F.W.S. Breeding Bird Survey data, 1961-1991.

* Species with a significant decline $(P<0.05)$; for all other species, declines are not statistically significant $(P>0.05)$. Year-to-year variability in avian populations often results in lack of statistical significance in declining populations. Lack of statistically significant decline does not, in itself, indicate that a species is maintaining healthy population levels.

found that trampling of waterfowl nests in non-rotational pastures occurred at a constant rate animal ${ }^{-1}$ day $^{-1}$, regardless of stocking rate $\left(\leq 10\right.$ animals ha ${ }^{-1}$ and $>10$ animals $\left.\mathrm{ha}^{-1}\right)$ or field size $(<2.5$ ha, 2.5-5 ha, and $>5 \mathrm{ha}$ ).

Other studies of ground nest trampling conducted on native rangeland in the western U.S. suggest a less clear-cut relationship between step density and nest trampling (Bareiss et al. 1986, Jensen et al. 1990, Koerth et al. 1983, Mesmer 1985). In addition, most of these studies, including Bientema and Müskens (1987), evaluated the effects of stocking densities lower than and pastures larger than those currently being used on midwestern dairy farms. A single study involved stocking densities similar to those used in this area. Jensen et al. (1990) used clay pigeon targets as simulated nests to study cattle trampling on tall grass prairie in Oklahoma. Animal number was held constant (at 3 head treatment $^{-1}$ ) for all treatments and higher stocking densities were achieved by reducing paddock size. Herd size affects animal movement and grazing behavior (Hacker et al. 1988), and one cannot assume that a herd of 3 animals in a 0.06 ha paddock will cause the same amount of nest destruction as 50 animals in a 1 ha paddock. Reduction of paddock size also increased nest density (20 nests paddock ${ }^{-1}$ were used for all treatments) and reduced forage allowance animal ${ }^{-1}$, which may also influence the amount of nest trampling observed.

Intensive rotational grazing of dairy cows employs small paddocks of non-native cool-season grasses, brief grazing periods, and a narrow range of relatively high stocking densities. To evaluate the effect of these grazing conditions on survival of ground nests, we compared a range of stocking densities and grazing period lengths recommended by the University of Wisconsin Extension Service for farmers in the northeastern and midwestern United States. Our objectives were 1) to determine whether short duration Intensive Rotational Grazing (IRG) is likely to cause greater ground nest destruction than longer term rotations with lower stocking rates, 2) to determine whether diurnal cattle behavior patterns influence trampling patterns, and 3) to evaluate the role of vegetation structure in trampling patterns.

\section{Study Site}

We conducted the study during the grassland songbird nesting season (May and June) (USFWS, unpubl. data) at the University of Wisconsin's Lancaster Agricultural Research Station (LARS) in southwestern Wisconsin. The area is characterized by rolling terrain, with 6 to $15 \%$ slope. The soils are Rozetta silt loams (Typic Halpludalf). Climate in this region is temperate with a 30 year average temperature range of $9.3^{\circ} \mathrm{C}$ (January) and to $22.2^{\circ}$ $\mathrm{C}$ (July). In 1993 , the mean temperature during May was $14.4^{\circ} \mathrm{C}$ \pm 3.99 (30-year mean $=14.5^{\circ} \mathrm{C} \pm 1.95$ ). The mean temperature in June was $18.1^{\circ} \mathrm{C} \pm 3.85$ (30-year mean $\left.=19.6^{\circ} \mathrm{C} \pm 1.37\right)$. Precipitation falls primarily as rain between March and November. Rainfall during the 1993 nesting season was $389 \mathrm{~mm}$, nearly twice the 30 year mean for the area $(189.5 \mathrm{~mm} \pm 50.6)$.

\section{Materials and Methods}

\section{Pastures.}

We used New Zealand-style portable electric fencing (Kingsbery 1989) to divide 3 pre-existing pastures into 12 paddocks, each 1.2 ha in size. In designing the layout of paddocks, we minimized differences that might influence cattle behavior, such as paddock shape, slope, and vegetation; location of feeding (supplemental grain was fed at $1.8 \mathrm{~kg}$ animal $^{-1}$ day $^{-1}$ ) and watering stations; and presence of trees within the paddock or adjacent wooded areas. Pasture vegetation was dominated by smooth bromegrass (Bromus inermis Leyss.), orchard grass (Dactylis glomerata L.), quackgrass (Agropyron repens L.), and Kentucky bluegrass (Poa pratensis L.). Red clover (Trifolium pratense L.) comprised 5 to $10 \%$ of pasture vegetation in most areas.

\section{Grazing Treatments.}

To ensure that we measured only the effects of cattle stocking density and grazing duration on trampling damage, we held constant factors such as paddock area (1.2 ha), forage allowance ani$\mathrm{mal}^{-1}\left(18 \mathrm{~kg} \mathrm{day}^{-1}\right)$, and nest density (12.5 nests ha $\left.{ }^{-1}\right)$, which may interact with stocking density. We used the research station's LARS herd of 130 yearling angus-Holstein beef heifers (Bos taurus L.) to apply grazing treatments to the paddocks. The heifers were mature, non-lactating animals with a mean weight of 500 $\mathrm{kg}$. Forage allowances were based on 1 heifer $=1$ animal unit (AU) (Forage and Grazing Terminology Committee 1991). We compared 3 rotational grazing treatments: a 1-day dairy rotation stocked with $72 \mathrm{AU}\left(60 \mathrm{AU} \mathrm{ha}^{-1}\right)$; a 4-day beef rotation stocked with $18 \mathrm{AU}$ (15 $\mathrm{AU} \mathrm{ha}^{-1}$ ); and a 7-day rotation that is commonly 
used by many farmers who are not grazing "intensively," stocked with $9 \mathrm{AU}\left(8 \mathrm{AU} \mathrm{ha}^{-1}\right)$. These treatments represent 72 animal unit days (AUD) for the 1- and 4-day rotations (72X1 day and 18X4 days for the 1- and 4-day treatments, respectively), and 63 AUD for the 7-day rotation ( $9 \times 7$ days).

Each treatment was randomly assigned to 4 of the 12 paddocks initially and was rotated among these 4 paddocks during the 8 consecutive weekly replications. Grazing for all treatments began on Tuesday of each week. The entire herd was pooled prior to the start of grazing and animals were assigned randomly to 1 of the 3 grazing treatments each week. Animals assigned to the 1- and 4day rotations were removed from the paddock following the designated number of days and grazed elsewhere on the farm until the following Tuesday. The 7-day rotations were run consecutively, with new animals assigned to a new paddock each Tuesday. Because the focus of this study was trampling damage, nests were monitored only during the grazing period of the rotational cycle. After each grazing treatment was completed, nests were removed and paddocks were rested for 2 to 4 weeks, depending on vegetation growth.

\section{Simulated Nests.}

Fifteen nest sites were located systematically in each paddock for a nest density of 12.5 nests ha ${ }^{-1}$. Wooden stakes driven flush with the ground were used to mark nest sites. A simulated nest, consisting of 3 unwashed pheasant (Phasianus colchicus L.) eggs, was placed $\leq 3 \mathrm{~cm}$ from each stake. No effort was made to form a nest bowl or to locate the nest in vegetative cover. Nest placement and construction vary considerably among grassland songbird species and choice of a particular method of 'hiding' nests may influence results. Nests were observed 4 times daily, corresponding to the beginning of cattle grazing cycles (0630 and 1530 hours) and rumination/rest cycles (1000 and 1900 hours).

The fate of each egg was recorded separately. Egg fates were grouped into 3 general categories: intact, disturbed or destroyed. For eggs that were disturbed or destroyed, we recorded whether disturbance resulted from cattle activity or from other causes such as predation. Efforts were made to locate eggs that had been moved from the vicinity of the marker stake and their fates were recorded when possible.

\section{Definition of Nest Survival.}

A nest was defined as the area $\leq 15 \mathrm{~cm}$ from the nest site marker stake (based on the size of an "average" songbird nest). Only eggs within this area were considered in determining nest survival. Eggs that had been moved $>15 \mathrm{~cm}$ from the stake were recorded as missing from the nest.

A nest containing 2 or 3 intact eggs at the time of observation was recorded as having survived, if no eggs were trampled $\leq 15$ $\mathrm{cm}$ from the stake. If $\geq 1 \mathrm{egg}(\mathrm{s})$ were trampled within this area, the nest was recorded as trampled (failed), regardless of the fate of the other egg(s). Nests that did not contain trampled eggs, but contained $<2$ intact eggs were recorded as failed.

\section{Vegetation Measurement.}

Vegetation structure was measured at the beginning and end of each grazing replication. Vegetation measurements were taken at each nest site and included height-density or visual obstruction (Robel et al. 1970) and percent vegetative cover (Daubenmire 1959). Pasture standing crop and removal were estimated by clip- ping a $0.5 \mathrm{~m}^{2}$ sample from 15 randomly chosen sites in each paddock before and after grazing (Campbell 1969, Carter 1962). Samples were weighed fresh, dried at $60^{\circ} \mathrm{C}$ for 48 hours, and reweighed for a determination of dry matter production.

\section{Statistical Analysis.}

Data were analyzed in 2 separate experimental designs. The original 15 clutches of eggs placed in each paddock at the start of each replication were monitored until they were no longer intact. These data were used to compare trampling damage and nest fates resulting from grazing treatments (objective No. 1) and were analyzed as a split plot with weeks as main plots and treatments as subplots, using general linear models and linear regression analyses (SAS Institute 1987). Because the study was replicated in time, we partitioned error resulting from this variable. No significant differences among weeks were observed for any of the analyses reported herein $(P>0.05)$.

For objectives No. 2 and No. 3, we replaced trampled or missing eggs after each nest observation, providing an equal number of nests in the paddocks during each of the diurnal grazing and rumination periods. For objective No. 2 , these data were analyzed as a split plot using general linear models (SAS Institute 1987), with diurnal time period as the split within grazing treatment. For objective No. 3, we compared the number of trampling events occurring at each nest site over the entire rotation with vegetation status using correlation analysis (SAS Institute 1987). Statistical significance for all analyses was defined at $\mathrm{P} \leq 0.05$ unless otherwise stated in the text.

\section{Results and Discussion}

\section{Effects of Grazing Treatment on Trampling Damage.}

For all treatments, about $25 \%$ of the original 15 nests survived the grazing cycle. Intact nests averaged $21 \pm 5.6 \%, 26 \pm 6.7 \%$, and $27 \pm 4.1 \%$ for the 1-, 4-, and 7-day treatments, respectively, with no statistically significant differences. The fact that the 7-day treatment involved fewer animal unit days (63 AUD) than the 1and 4-day treatments (72 AUD) may have influenced relative nest survival among the treatments and should be kept in mind when interpreting the data presented.

In the majority of cases ( $94 \%$ of failed nests), nest failure was from cattle damage, including crushing by an animal's muzzle, trampling by hoof, or being kicked out of the nest. The remainder of the failed nests were not damaged by cattle but lacked the required $\geq 2$ eggs intact. Predation was the primary cause of nest failure among untrampled nests. Predation of nests was greater for the 7-day treatment than for the 1- and 4-day treatments. Most predation of nests occurred during early June (weeks 5 and 6 ) between 1900 and 0600 hours.

\section{Types of Trampling Damage.}

Most, but not all, cattle disturbance resulted in nest failure. When all forms of cattle disturbance $(\geq 1 \mathrm{cgg}(\mathrm{s})$ trampled, crushed by an animal's nose, kicked out of the nest and crushed or cracked, or covered with a manure pile) were totaled, disturbed (but not necessarily failed) nests averaged $81 \pm 5.3,77 \pm 6.8$, and $65 \pm 4.8 \%$ (of 15 nests) for the 1-, 4-, and 7-day treatments, respectively, with no significant differences among treatments. However, there were differences among treatments for specific types of disturbance. The mean percentage of the 15 nests having 
$\geq 1 \mathrm{egg}(\mathrm{s})$ trampled by a bovine hoof, was greater for the 1-day treatment $(63 \pm 6.5 \%)$ than for the 4-day $(52 \pm 6.6 \%)$ or the 7-day $(41 \pm 3.4 \%)$. The 1-day treatment had a higher percentage of trampled nests with 2 or 3 eggs crushed ( $82 \pm 9 \%$ of trampled nests) than the 7- day treatment (65 $\pm 13 \%$ of trampled nests), but not significantly higher than the 4-day treatment $(77 \pm 11.9 \%$ of trampled nests). Greater numbers of crushed eggs may be the result of nests having been trampled $>1$ time between observations. A greater percentage of nests in the 4-and 7-day treatments had eggs kicked out of the nest or otherwise damaged by cattle than the 1-day treatment. For all treatments, most of the 15 nests that survived had all 3 eggs intact $(84 \pm 6.5,75 \pm 6.2$ and $58 \pm 3.8 \%$ of intact nests for the 1-, 4-, 7-day rotations, respectively).

\section{Individual Animal Contribution to Trampling.}

The mean trampling rate per AUD was 0.165 $\pm 0.012,0.153 \pm$ 0.014 , and $0.173 \pm 0.01$ for the $1-, 4-$, and 7 -day treatments, respectively, with no significant differences among treatments. Regression analysis yielded a linear pattern of trampling for both the 4 - and 7 -day treatments $(\mathrm{P}<0.01)$, although the data suggest a slight leveling of the trampling rate as AUD accumulated for both treatments (Fig. 1).

For the 4-day treatment: \# Nests Trampled $=0.17$ (cumulative \# of AUD)

(Standard Error $=0.009, \mathrm{R}$-square $=0.92$ )

For the 7-day treatment: \# Nests Trampled=0.2(cumulative \# of AUD)

(Standard Error=0.007, R-square $=0.93$ )

\section{The Role of Cattle Diurnal Behavior Patterns in Nest Destruction.}

Cattle typically graze and ruminate in a diurnal pattern (Campbell et al 1969, Sheppard et al. 1957). Peak grazing periods are from dawn until late morning and from late afternoon until dusk. During midday and night rest/rumination periods, cattle are typically less active than while grazing (Campbell et al. 1969). We found that the number of nests damaged during each of these periods was associated with cattle daily behavior patterns and

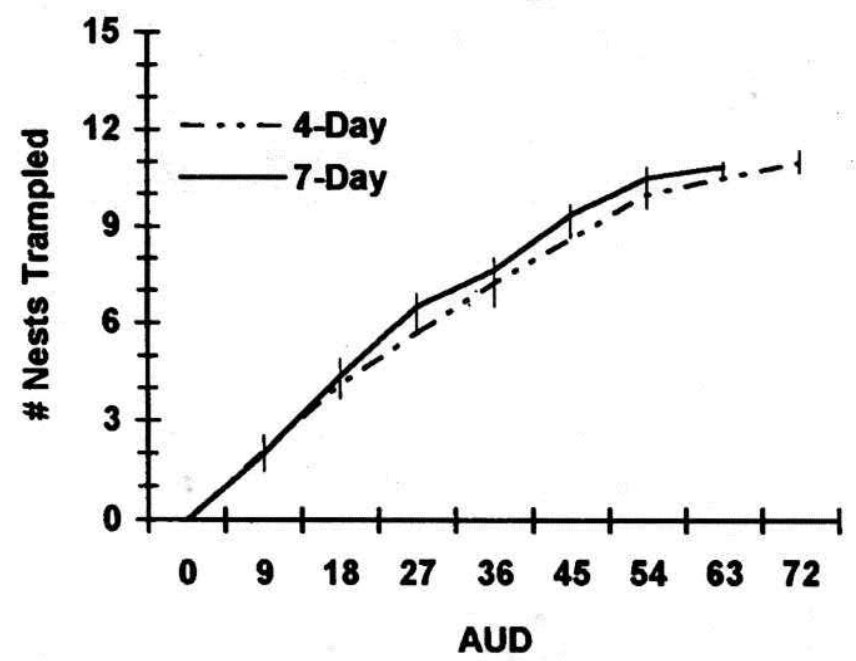

Fig. 1. Mean number of original 15 nests trampled animal unit day (AUD) ${ }^{-1}$ over treatment period for 4- and 7-day treatments. Vertical lines indicate standard errors of 8 replicates.

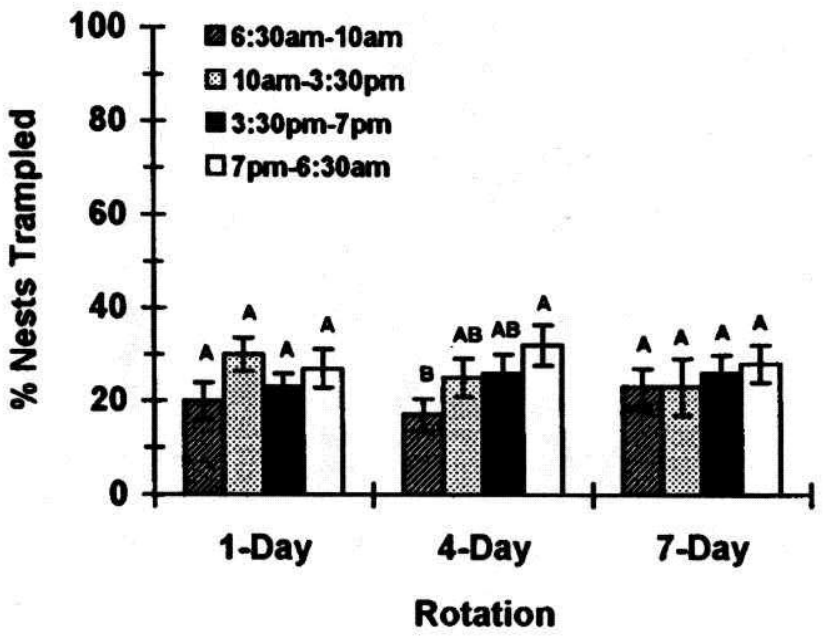

Fig. 2. Percentages of total nests trampled during cattle daily grazing and rumination periods. Vertical lines indicate standard errors of 8 replicates. Mean separation within treatment by LSD at $P<0.05$. Bars with the same letter are not significantly different. Note: 6:30 am-10 am and 3:30 pm-7 pm are grazing periods; 10 am-3:30 pm and 7 pm-6:30 am are rest/rumination periods.

activity levels. However, for all treatments, $\leq 32 \%$ of the nest damage occurred during any of the 4 daily periods (Fig. 2).

The diurnal trampling pattern for the 1-day treatment differed significantly from the pattern observed in the 4- and 7-day treatments (Fig. 2). For the 1-day treatment, the midday rumination period accounted for $30 \pm 3.7 \%$ of daily nest damage; this was greater than the overnight period, which was $>2$ times as long. This result may be an artifact of experimental design rather than a reflection of typical animal activity during rumination. For logistical reasons, all treatments were begun at 1000 hours, just at the start of this rumination or rest period. Moving cattle to fresh pasture frequently results in a period of exploration and/or grazing regardless of where they are in their diurnal cycle (Arnold and Dudzinski 1978). The high trampling rate observed for this normally less active period may reflect this disruption of their normal behavior patterns. The phenomenon was not observed in the longer treatments because, in these treatments, the animals remained in the same paddock for several days and subsequent midday rumination periods were not interrupted by a move to a new paddock. There were no significant differences in numbers of nests damaged among diurnal periods within either the 4- or 7day treatments.

Because the grazing and rumination periods varied in length, it is useful to compare hourly rates of trampling among the 4 daily periods. The night period, which was $>11$ hours, was $>2$ times as long as any other sampling period and the total percentage of nests destroyed was relatively high. However, the trampling rate animal $^{-1}$ hour $^{-1}$ was lowest at night for all treatments (Fig. 3).

We hypothesized that higher nest trampling rates would occur during grazing periods (dawn to midmorning and late afternoon to dusk) than during rest or rumination periods (midday and during the night). Only the 7-day treatment fit this pattern. For the 1day treatment, hourly trampling rates for all daytime periods were similar, but the overnight rate was significantly lower (Fig. 3). For the 4-day treatment, the afternoon grazing period had the greatest hourly trampling rate, while the other daytime and the 


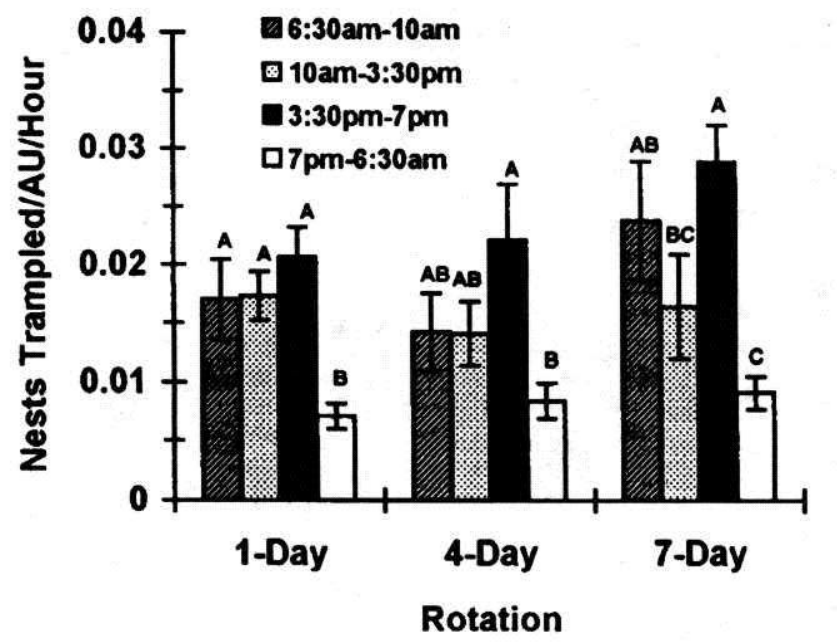

Fig. 3. Hourly rates of trampling animal ${ }^{-1}$ for rotations and time periods. Vertical lines indicate standard errors of 8 replicates. Mean separation within treatment by LSD at $P<0.05$. Bars with the same letter are not significantly different. Note: $6: 30 \mathrm{am}-10 \mathrm{am}$ and 3:30 pm-7 pm are grazing periods; $10 \mathrm{am}-3: 30 \mathrm{pm}$ and $7 \mathrm{pm}-$ $6: 30$ am are rest/rumination periods.

overnight periods were similar. In contrast, the 7-day treatment had significantly greater hourly trampling rates animal ${ }^{-1}$ during the 2 grazing periods than during the 2 rumination periods. As herd size decreased, the difference in trampling rates among the daytime periods increased, probably reflecting less randomness in animal behavior and movement in smaller herds. Cattle take behavioral cues from nearby animals (Dwyer 1961, Roath and Krueger 1982) and the larger the herd, the less influence any 1 animal has on the behavior of other herd members. A large herd is less likely to exhibit a typical grazing-ruminating pattern, so that activity levels are more constant, resulting in a more constant rate of nest trampling.

\section{Relationship Between Nest Destruction and Vegetation Status.}

Vegetation growth was influenced by abnormally high rainfall during the 1993 growing season. As a result of greater than normal forage availability, only in the 1-day treatment was postgrazing height-density (H-D) consistently lower than pre-grazing levels (Fig. 4). Half of the rotations in the 4-day and $75 \%$ in the 7-day rotation had similar or higher post-grazing than pre-grazing H-Ds.

In general, nest destruction (number of trampling events) decreased with increasing vegetation H-D and percent cover. While several correlations were statistically significant, few correlation coefficients were $>0.50$. Pre- and post-grazing percent live vegetation cover at the nest site were negatively correlated with nest destruction for all treatments, except pre-grazing percent cover for the 7-day treatment (Table 2). Negative correlations between number of trampling events at each nest site and both pre- $(-0.23)$ and post-grazing $(-0.42) \mathrm{H}-\mathrm{D}$ at that nest site also were statistically significant for the 1-day treatment $(P<0.01)$ (Table 2). Mean paddock H-D both before $(-0.65)$ and after $(-0.67)$ grazing was negatively correlated with nest destruction for the 1day treatment only $(P<0.10)$ (Table 2$)$, suggesting that when forage is plentiful, animal movement in a large herd during grazing
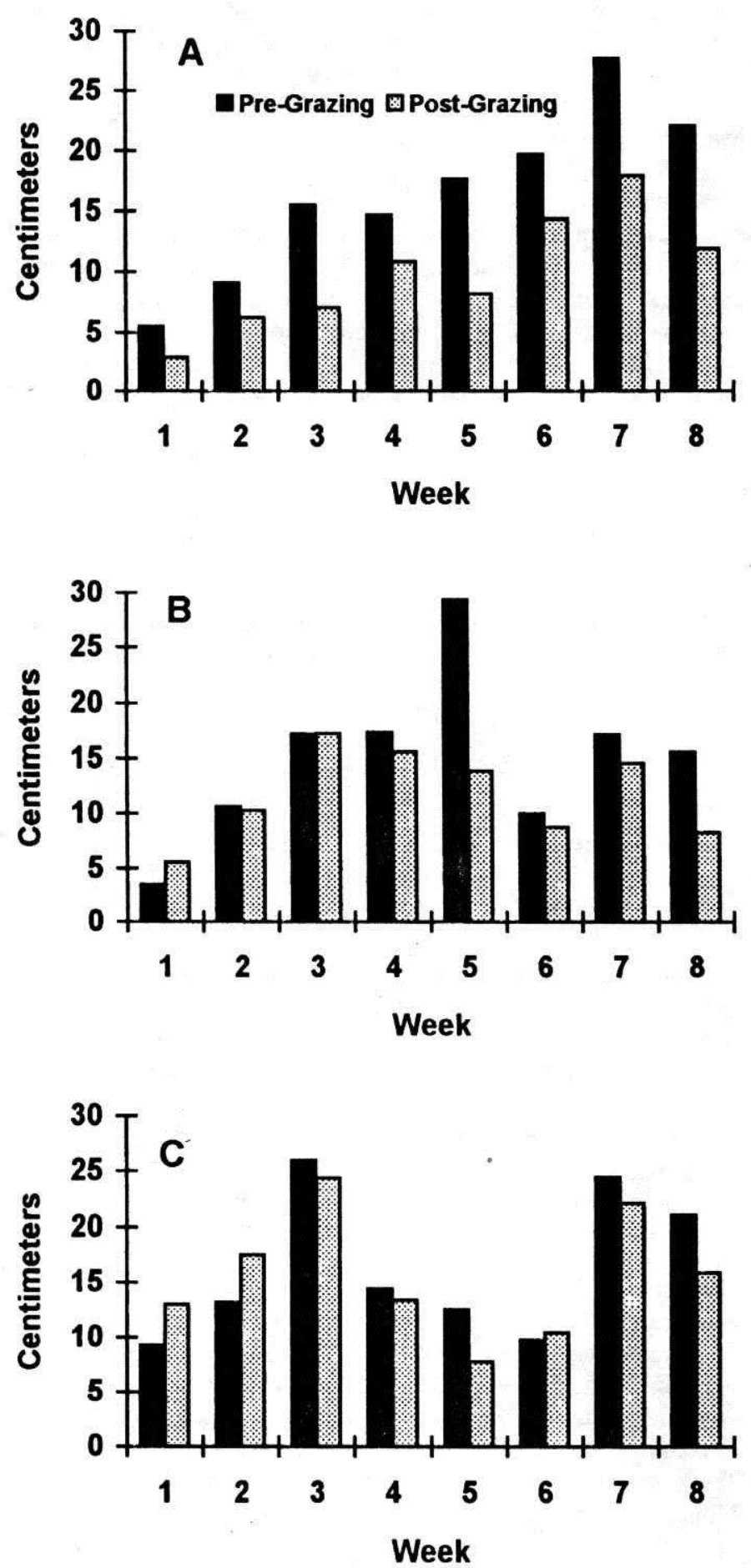

Fig. 4. A-C. Vegetation height-density in centimeters before (solid bars) and after (hatched bars) grazing for each of the 8 consecutive weekly replications. $A=1$ day of grazing @ 60 Animal Units (AU) $\mathrm{ha}^{-1} ; \mathrm{B}=4$ days of grazing @ $15 \mathrm{AU} \mathrm{ha}{ }^{-1} ; \mathrm{C}=7$ days of grazing (a) $8 \mathrm{AU}^{-1}$.

decreases, possibly resulting in less trampling of nests. Significant negative correlations between vegetation status and nest destruction were not observed in the 4- and 7-day treatments because animal consumption did not keep pace with vegetation growth. Nest destruction was negatively correlated only with 
Table 2. Correlation of paddock mean vegetation height-density (H-D) and $\%$ live cover (\% Cover) with mean number of trampling events (Paddock Mean) and correlation of vegetation height-density and $\%$ live cover at each nest site with number of trampling events at that nest site (Nest Site).

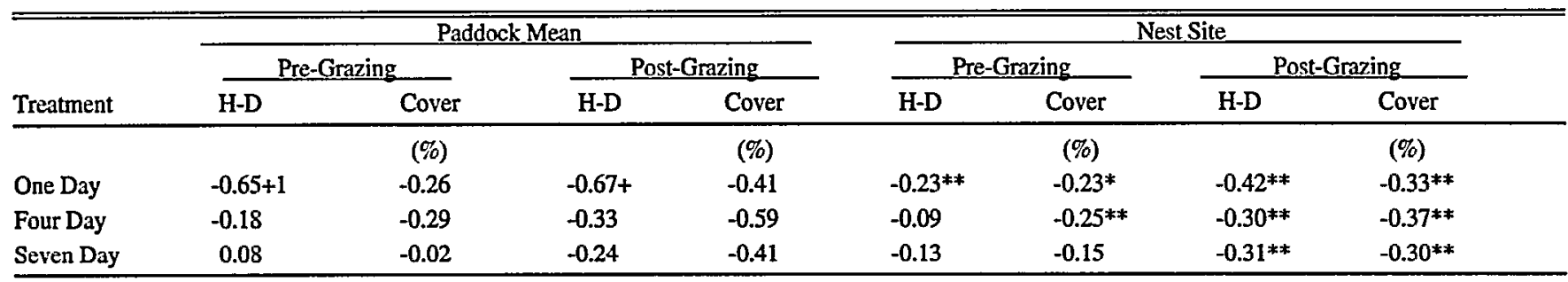

$1_{+=P<0.1, *=P<0.5, * *}^{*}=P<0.01$.

post-grazing H-D at the nest site for the 4- $(-0.30)$ and 7-day $(-0.31)$ treatments $(P<0.01)$. However, this relationship is probably not one of cause and effect. It is more likely that both may be associated with a lack of animal grazing activity in the parts of the paddock where untrampled nests were observed.

Forage dry weight, while correlated with height-density and percent live cover, did not correlate significantly with nest trampling or survival. Forage removal was not correlated with nest trampling for any treatment.

\section{Management Implications}

In this comparison among 3 rotational grazing systems (all involving about 70 animal days treatment ${ }^{-1}$ ), we found that the amount of trampling damage to simulated nests did not vary among the treatments. A mean of $75 \%( \pm 3.1 \%)$ of the original 15 nests was destroyed per grazing cycle under each of the treatments. Trampling damage was spread fairly evenly throughout the daily activity cycle of the herd, with somewhat more nest destruction hour $r^{-1}$ occurring during the afternoon grazing period. Manipulation of herd activity will not improve nest survival, except in terms of reducing the trampling that occurs when the cattle are put on fresh pasture. A reduction in trampling damage to nests might be gained by introducing cattle into the paddock during an active grazing period, to minimize damage during the rumination period.

If grazing is managed for forage productivity, stocking density and rotation length will vary inversely. Under recommended pasture management, the number of animal unit days varies little among rotational systems. Using a grazing cycle with both a short duration grazing period and a relatively high stocking density maximizes the amount of time that the pasture is left undisturbed between grazing events and causes no more nest destruction than longer grazing cycles using lower stocking densities. Some nest protection may be gained by introducing the animals into the paddock at a greater vegetation height-density and leaving a relatively large amount of residue post-grazing. These factors can be varied within certain limits without affecting the vegetation growth cycle or forage quality (Blaser et al. 1986). Manipulation of vegetation status may increase nest survival at high stocking densities, but this effect will be minimal at lower stocking densities.

\section{Literature Cited}

Arnold, G.W. and M.L. Dudzinski. 1978. Ethology of free ranging domestic animals. Elsevier, New York, N.Y..

Bareiss, L.J., P. Schulz, and F.S. Guthery. 1986. Effects of short-duration and continuous grazing on bobwhite and wild turkey nests. J. Range Manage. 39:259-260.

Basore, N.S., L.B. Best, and J.B. Wooley. 1986. Bird nesting in lowa no-tillage and tilled cropland. J. Wildl. Manage. 50:19-28.

Bientema, A.J. and G.J.D.M. Müskens. 1987. Nesting success of birds breeding in Dutch agricultural grasslands. J. Appl. Ecol. 24: 743-758.

Blaser, R.E., R.C. Hammes, Jr., J.P. Fontenot, H.T. Bryant, C.E. Polan, D.D. Wolf, F.S. McClaugherty, R.G. Kline, and J.S. Moore. 1986. Forage-animal management systems. Virg. Agric. Exp. Sta. Bull. 86-7, Blacksburg, Virg..

Bryant, F.C., F.S. Guthery, and W.M. Webb. 1982. Grazing management in Texas and its impact on selected wildlife, p. 94-112. In: J.M. Peek and P.D. Dalke (eds.). Wildlife-livestock relationships symposium. Proc. 10. Univ. Idaho Forest. Wildl. and Range Exp. Sta., Moscow, Ida.

Campbell, J.B. 1969. Experimental methods for evaluating herbage. Can. Dep. Agric. Publ. 1315. The Queen's Printer, Ottawa.

Campbell, J.B. E. Stringam, and P. Gervais. 1969. Pasture activities of cattle and sheep. Can. Dep. Agric. Pub. 1315: 105-112.

Carter, J.F. 1962. Herbage sampling for yield: tame pastures, p. 90-101. In: G.O. Mott et al. (eds.) Pasture and range research techniques. Comstock Publ. Assoc., Ithaca, N.Y..

Castrale, J.S. 1987. Pesticide use in no-till row-crop fields relative to wildlife. Ind. Acad. Sci.. 96: 215-222.

Daubenmire, R. 1959. A canopy-coverage method of vegetational analysis. Northwest Sci. 33: 43-64.

Dwyer, D.D. 1961. Activities and grazing preferences of cows with calves in northern Osage County. Okla. Agric. Expt. Sta. Bul. 588.

Fales, S.L. 1993. Where do pastures fit in dairying? p. 76-85. In: L. Paine and D. Undersander (eds.) Alfalfa: in pursuit of excellence. Proc. 23rd Natl. Alfalfa Symp. Certified Alfalfa Seed Council. Madison, Wisc.

Forage and Grazing Terminology Committee. 1991. Terminology for grazing lands and grazing animals. Pocahontas Press, Inc., Blacksburg, Virg..

Frawley, B.J. and L.B. Best. 1991. Effects of mowing on breeding bird abundance and species composition in alfalfa fields. Wildl. Soc. Bull. 19: 135-142.

Hacker, R.B., B.E. Norton, M.K. Owens, and D.O. Frye. 1988. Grazing of crested wheatgrass, with particular reference to effects of pasture size. J. Range. Manage. 41: 73-78.

Herkert, J.R. 1994. The effects of habitat fragmentation on midwestern grassland bird communities. Ecol. Applic. 4: 461-471.

Jensen, H.P., D. Rollins, and R.L. Gillen. 1990. Effects of cattle stock density on trampling loss of simulated ground nests. Wildl. Soc. Bull. 18: 71-74.

Kingsbery, B. 1989. How to plan, implement and practice controlled grazing on your place. Kingsbery Communications, Woodinville, Wash. 
Koerth, B.H., W.M. Webb, F.C. Bryant, and F.S. Guthery. 1983. Cattle trampling of simulated ground nests under short duration and continuous grazing. J. Range Manage. 36: 385-386.

Messmer, T.A. 1985. Effects of specialized grazing systems on upland nesting birds in southcentral North Dakota. M.S. Thesis. N.D. State Univ., Fargo, N.D..

Roath, L.R. and W.C. Krueger. 1982. Cattle grazing and behavior on a forested range. J. Range Manage. 35: 332-338.

Robel, R.J., J.N. Briggs, A.D. Dayton, and L.C. Hulbert. 1970. Relationships between visual obstruction measurements and weight of grassland vegetation. J. Range Manage. 23: 295-297.
SAS Institute. 1987. SAS/STAT Guide for personal computers, Version 6 edition. Cary, N.C.

Sheppard, A.J., R.E. Blaser, and C.M. Kincaid. 1957. The grazing habits of beef cattle on pasture. J. Anim. Sci. 16: 681-687.

Undersander, D.J., B. Albert, P. Porter, and A. Crossley. 1991. Wisconsin pastures for profit: a hands on guide to rotational grazing. Univ. Wis. Cooperative Ext. Pub. A3529. Madison, Wisc.

Voisin, A. 1959. Grass productivity. Philosophical Library. New York, N.Y.

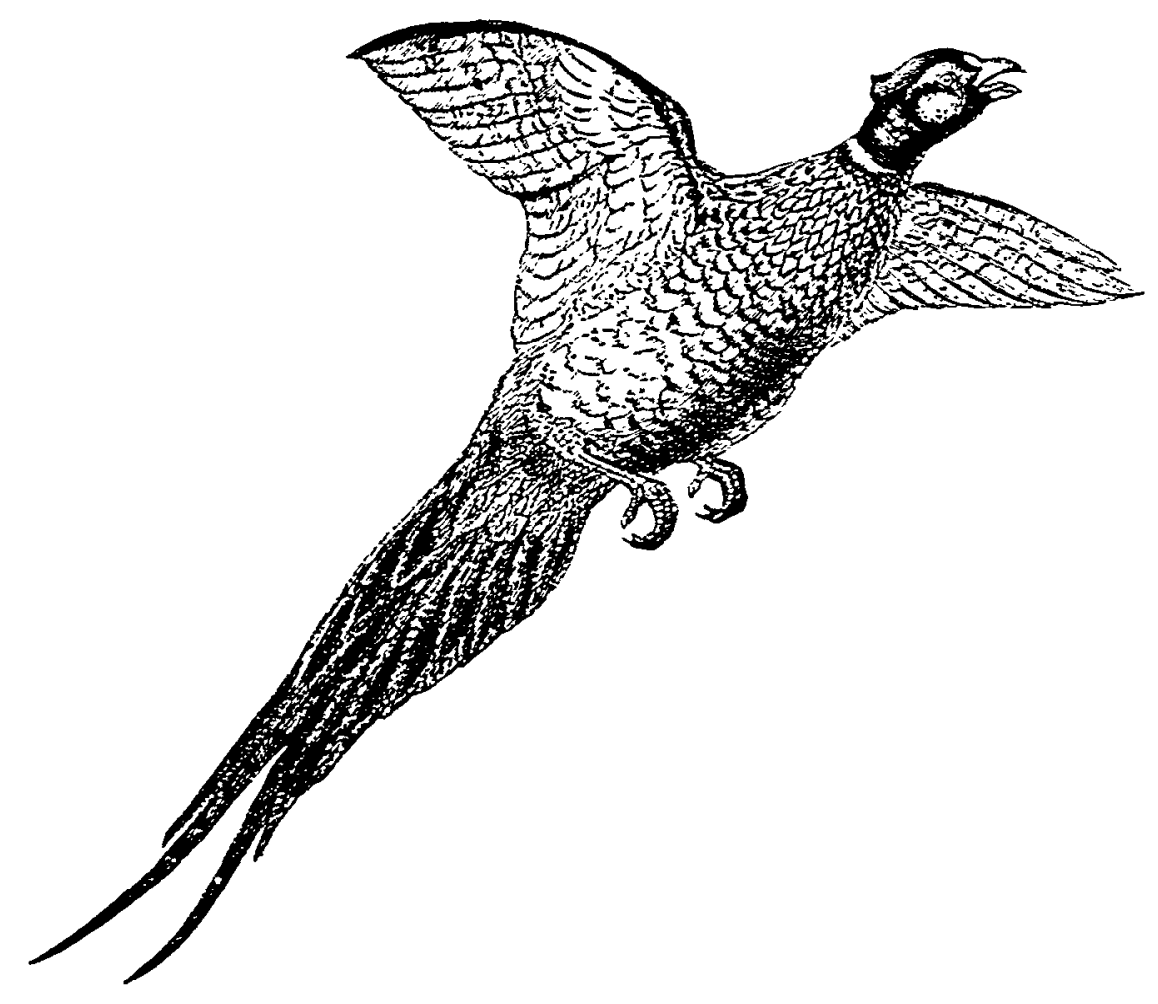

